\title{
research
}

\section{"We're not a bottomless pit": food banks' capacity to sustainably meet increasing demand}

\author{
Steve lafrati, s.iafrati@wlv.ac.uk \\ University of Wolverhampton, UK
}

Based on research with 21 food banks across eight local authority areas in England, this article examines the sustainability of food banks in their attempts to balance demand and supply. Against a background of multiple deprivation and welfare reforms in the UK, food banks are becoming increasingly important for growing numbers of people. However, at a time when food banks' ability to meet this increasing demand is close to capacity, this article examines how social purpose is a core element in food banks' understanding of sustainability. With food banks having little control over the level of demand, and supply being increasingly close to capacity, if demand exceeds supply, sustainability will necessitate either denying demand or expanding supply.

key words food banks $\cdot$ sustainability $\cdot$ demand and supply $\cdot$ poverty

\section{Introduction and argument}

Based on research with managers ${ }^{1}$ at 21 food banks across the East and West Midlands in England during late 2016 and 2017, this article examines the challenges that food banks face in meeting increasing levels of demand. Exploring the sustainability of food banks, it looks at both the benefits and constraints of being within the voluntary sector. While the food banks involved in the research were broadly meeting demand at the time of the research, it is important to realise that this cannot be guaranteed in the future. Food banks are not, as one respondent put it, "a bottomless pit".

A key challenge facing food banks comes from persistently increasing demand, with food banks in the research identifying an increase of approximately 5\% in 2016 compared with the previous year (Black Country Food Bank Network, 2016; Trussell Trust, 2017a). While this is a slower rate of growth than in previous years, meeting increasing demand in the future will necessitate food banks increasing their capacity to supply. Understanding the balance between supply and demand in welfare provision is nothing new (Salamon and Anheier, 1998; Fontaine, 2002; Reisman, 2004). However, while this has been typically applied to taxation and spending within state welfare, there is no reason why this cannot be applied to the voluntary sector and, specifically, food banks. Linking this to sustainability, it can be argued that should demand grow beyond the capacity of supply to meet that demand, food banks will be faced with the challenge of how to ration provision.

This article argues, first, that food bank sustainability is defined by the balance between the supply of resources and the level of demand; but second, that because 
meeting demand is key to food banks' sense of social purpose, sustainability for them is also defined by their continuing ability to do so whatever the resource constraints.

The importance of this article is that it examines the capacity of food banks, as voluntary sector organisations (VSOs), to sustainably provide essential welfare to growing numbers of people. Furthermore, the article reflects on expectations placed on food banks and how increasing demand might challenge their ability to meet these expectations. Consequently, this article is not an examination of poverty or the reasons why people use food banks. Instead, it looks at the capacity ofVSOs to sustainably meet people's need to use food banks.

To date, most food bank research, for important reasons, has examined the issue of demand. This locates food banks within debates about poverty, outcomes of government policy such as welfare reforms, and the economic impacts of the growing precariousness of work (Cooper et al, 2014; Tsilimpounidi et al, 2014; Loopstra et al, 2016). In this respect, existing literature does not specifically look at the operation of food banks, but rather the experiences of people using food banks and the political economy of their growth. This is an important issue given the rapid growth in food banks and the way in which they form an essential element of many people's welfare. Recognising this point, food bank managers in this research saw no sign of demand declining amidst the failings of the economy and mainstream welfare to meet the needs of a growing number of people. However, they also recognised the importance of understanding the risks that food banks face in sustainably meeting these people's needs.

Next, this article details the methodology used in the research before setting the context of increasing demand at food banks due, in part, to people's experiences of work, welfare reforms and economic challenges facing the areas covered by the research. Important to the article's argument, this identifies the challenges that food banks face in meeting increasing demand and the possibility of demand, at some point, exceeding supply. With this in mind, the article subsequently examines the concept of sustainability as a way to understand the balance between supply and demand. Critically, this includes looking at how definitions of organisational sustainability do not fully explain food bank managers' prioritisation of social purpose over organisational factors. The research findings consequently reflect on food bank managers' experiences as they seek to sustainably meet demand without turning people away.

\section{Research methodology}

The research was based on semi-structured interviews with food bank managers to ensure context and focus for the interviews while not wanting to limit or guide the respondents' answers. Mindful of the research objectives, the questions focused on the managers' experiences of food bank capacity, planning, partnerships and sustainability. In particular, the questions gave the managers the opportunity to raise issues they felt important and recognised how the managers were predominantly driven by goals of addressing social justice and feeding people in need of food. The article therefore presents an understanding of food bank managers' experiences of change, development and sustainability over the past few years.

As part of the voluntary sector, food banks represent diverse organisations that, despite their variety, share a common theme of valuing the independence of decision 
making. Recognising this diversity, the research was based on interviews with food bank managers across the East and West Midlands in the UK. In total, 21 food banks were included, covering eight local authority areas, in order to produce a breadth of results that may be generalisable to food banks in other parts of the UK. The goal of the research was to explore food banks' supply capacity and their sustainability in order to complement existing studies on food bank demand. The research also included two network events where food bank representatives met together to discuss relevant issues, giving the participants the opportunity to share experiences. Over 60 people attended the two events, from food banks, local authorities and allied voluntary sector organisations.

Food banks in the research were identified through various sources such as local authority guides, suggestions from other food banks and having an internet presence. Only a small number of food banks did not respond to the invitation to participate in the research, one (not included in the 21) had recently closed but provided a detailed written account of their activities, while another (also not included in the 21) would only be interviewed by people holding similar religious beliefs. Despite this, the number represents a cross-section of food banks from different geographies, faiths and non-religious organisations and with different socioeconomic client profiles.

The Trussell Trust, the largest network of food banks in the UK, has become their public face in the media and produces valuable data measuring food bank demand. However, of the 21 food banks in this research, only about a third are part of the Trussell Trust. The remaining food banks work either independently or as part of localised networks covering one or more local authority area. Thus, Trussell Trust data produced from their food banks, which has been widely used within the media, underestimates the full extent of food bank demand.

\section{Context}

\section{Increasing demand and sustainability}

Since the financial crisis in 2008, the Midlands in England has experienced slow economic growth coupled with comparatively low wages (D'Arcy, 2016; Harari, 2016). In addition to poor regional economic performance, for many people the experience of work has involved fractured and insecure employment (Shildrick et al, 2012; Pennycook et al, 2013; Pyper and Brown, 2016; Tinson et al, 2016). Looking at the economic characteristics of the areas covered in this article, Indices of Multiple Deprivation $^{2}$ for Birmingham and the Black Country ${ }^{3}$ range between 37.8 and 30.4 (with the exception of Dudley at 23), compared with a national score of 21.8. Similarly in the East Midlands, Leicester and Nottingham have measures of 33.1 and 36.9 respectively (DCLG, 2015). This means that there are pronounced levels of multiple deprivation in these areas. Furthermore, with growing numbers of families with children accessing food banks (Black Country Food Bank Network, 2016; Trussell Trust, 2017a), it is important to recognise that while $20.1 \%$ of under-16s are living in low-income families nationally, the figure is much higher in the areas covered by this research. In Birmingham and the Black Country, between 29.6\% and 32.9\% of children live in low-income families, with the exception of Dudley at $23.1 \%$. In the East Midlands, Leicester and Nottingham have comparable rates at $28.8 \%$ and 
$34.4 \%$ respectively and have the highest local authority child poverty rates in the East Midlands (Public Health England, 2014).

Other low-income indicators - such as benefit claimant count, children in workless households, average workplace earnings, long-term unemployment and people not in education, employment or training (NEET) (DfE, 2017; Nomisweb, 2017) - show similarly high levels in Birmingham, the Black Country, Leicester and Nottingham. Significantly, the data represent local authority averages, with poverty levels being even higher in many neighbourhoods. The overall impact is a greater demand for welfare at a time when welfare reforms since 2010 have led to financial losses for people accessing benefits. Specifically, Birmingham, the Black Country (except Dudley), Leicester and Nottingham are identified among the areas hardest hit from welfare reforms (Beatty and Fothergill, 2014, 2016).

While the level of poverty is above the national average in the areas covered by this research, the experience is not unique to the Midlands. This reflects similar experiences of poor economic growth, welfare reforms and precarious working in other parts of the country. Another area of generalisability is the role of religious organisations in providing food aid to growing numbers of people. This long-established charitable role for the faith sector has grown in response to recession, welfare reforms and austerity. Consequently, generalising this beyond food banks, many of the themes of this article are relevant across the voluntary sector as it takes on increasing levels of welfare provision amidst limited funding and heightened expectations.

The portrayal of food banks in films such as I, Daniel Blake and in the media is supported by data from the food banks in the research showing that a third of food is going to children (Black Country Food Bank Network, 2016; Trussell Trust, 2017a). Also, the Trussell Trust, Britain's largest social franchise, is now distributing over 1.1 million food parcels per year (Trussell Trust, 2016, 2017a), although as mentioned previously, this underestimates demand. In addition, a significant amount of food aid is distributed in unmonitored ways through organisations such as The Salvation Army, gurdwaras and mosques (McCabe et al, 2016; O’Toole and Braginskaia, 2016). Furthermore, there are numerous semi-formal groups distributing food and other welfare to people in need through ad-hoc outreach and pop-up services organised through social media.

Against this backdrop, understanding food banks in contemporary welfare has focused mainly on the growth in demand (Bull and Harries, 2013; Cooper and Dumpleton, 2013; Peachey et al, 2013; Cooper et al, 2014; Dowler and LambieMumford, 2014, 2015; Forsey and Mason, 2015) and people's experiences of using food banks (Garthwaite, 2016a). In the absence of practical assistance, it might be presumed that the government views food banks as being able to cope with demand and preferable to policy interventions that might reduce demand (Lambie, 2011; Lambie-Mumford, 2013; Downing et al, 2014; Lambie-Mumford et al, 2014; Tsilimpounidi et al, 2014; Garthwaite, 2016b). However, food bank sustainability and their capacity to meet demand cannot be taken for granted. With food banks providing 'a robust last line of defence against hunger' (Ashton et al, 2014, cited in Loopstra et al, 2015), their role is too important to too many people not to examine the relationship between supply and demand.

At the heart of this article therefore lies the concept of sustainability as food bank managers recognise the challenges presented by growing demand and finite capacity. Importantly, however, the evidence reported in this article suggests that for the food 
bank managers, sustainability includes a perception of the social purpose of feeding all those presenting at food banks.

Despite food bank managers' primary concern being the social purpose of meeting demand, literature relating to sustainability and the voluntary sector focuses instead on 'organisational sustainability', characterised by the National Council forVoluntary Organisations as being 'financially independent, celebrating volunteers, creating a learning environment, [and] encouraging wider involvement of volunteers' (Taylor and Donoghue, 2014). This typifies organisational sustainability as 'keep[ing] the business going' (Wales, 2013) or 'survivability' (Paxton et al, 2005) and is framed within resource management factors such as attracting volunteers (Ellis Paine, 2015).

However, within discussions of sustainability, there is some recognition that the concept is somewhat nebulous and, most importantly, has different applications for different settings (Low and Davenport, 2002; Lindsey, 2008; Harris and Young, 2010; Macmillan, 2010). Consequently, in relation to food banks, a generic understanding of organisational sustainability risks presenting a 'one-dimensional measure' of sustainability that overlooks social capital, added value (Chapman et al, 2010) and the primacy of meeting demand. The imperative of organisational sustainability would be to increasingly ration supply, thereby placing the food bank in control of the balance of demand and supply. However, the food bank managers were instead oriented towards a social purpose that defined food bank success through efficacy rather than organisational sustainability alone. In fact, an important finding of this article is that the food bank managers were more focused on the social purpose of food banks than organisational practicalities.

Some literature recognises the importance of the sustainability of social purpose to VSOs by examining 'person-centredness', meeting social goals and satisfying the needs of 'stakeholders' (Doherty et al, 2014; Manetti and Toccafondi, 2014; Rees and Rose, 2015; Martin et al, 2016; Glennon et al, 2017). However, to date, these elements of sustainability have only been applied to food banks to a limited extent (Lambie-Mumford, 2013, 2015; Iafrati, 2016), and even then, not always as part of an explicit focus on sustainability.

\section{Challenges associated with meeting demand}

To understand the challenges that food banks face, it is useful to make informed predictions about future demand based on changes in the factors currently driving demand (Trussell Trust, 2016, 2017a; Jitendra et al, 2017). Approximately half of food bank demand is caused by social security benefit delays and low income, with benefit changes and debt also being major causes (Trussell Trust, 2016). Looking at this in context, there was a rapid rise in food bank use after the 2008 financial crisis, identifying a link between food banks and economic crisis. However, a decade later, there remains significant and sustained food bank use that shows no sign of abating. In fact, some of the largest increases came after 2010 when, rather than economic crisis, there was significant politically driven change, redesigning the rules governing access to benefits.

For many food bank managers in the research, the rapid growth in demand from 2010 took them by surprise and has allowed them little time to plan future service provision. In contrast, since 2014, the rate of growth in food bank demand has slowed slightly, to approximately 5\% (Black Country Food Bank Network, 2016; Trussell 
Trust, 2017a). Recognising factors driving food bank demand (Trussell Trust, 2016, 2017a; Jitendra et al, 2017), the slower increase in demand may be linked to national factors such as the effects of the financial crisis diminishing, and while the UK is still feeling the effects of austerity, there is modest economic growth nationally and a declining use of benefit sanctions since the start of 2014 (DWP, 2017).

Consequently, food bank demand is shaped not only by economic factors, but also by their interaction with political factors. The impact of welfare reforms, delays and sanctions were major reasons why people sought out the support of food banks (Downing et al, 2014; Perry et al, 2014; Garratt, 2016; Loopstra et al, 2016). Furthermore, evidence shows that almost one million people are currently working on zero-hour contracts (ONS, 2017) with no guarantee of regular income. With further welfare reforms in April 2017 and the roll-out of Universal Credit, the impact will mean that many of the poorest families currently relying on benefits will see a significant decline in their income (Hood and Waters, 2017), which may fuel food bank demand.

Having recognised the reasons for food bank use, coupled with an awareness of welfare and economic changes, it might be considered likely that food bank demand will continue to rise at least at the current rate. However, it cannot be ruled out that further economic factors, such as growing household debt (Brazier, 2017; Harari, 2017) will lead to even greater increases in food bank demand. With evidence suggesting this to be the case, it is important to consider food banks' ability to sustainably meet demand without denying provision. To fully consider food banks' ability to meet increasing demand, it is necessary to consider their capacity to supply. To date, there has been very little focus on the supply element of food banks, with writers and researchers choosing instead to look at the demand elements as a way to examine poverty and people's experience of welfare reforms. Such studies, referenced earlier in the article, have been invaluable, but without understanding their relationship to supply, it is impossible to understand whether food banks will continue to be such a comprehensive last line of defence against hunger.

\section{Research findings}

Underpinning this article is the question of how food banks manage increasing demand and finite capacity. With this in mind, the findings consider challenges to supply and whether food banks, as VSOs, can continue working without entering into formal partnerships that would erode some of their autonomy. Significantly, for food bank managers in this research, autonomy and voluntary sector identity were important elements in defining their identity. With this article arguing that the balance between supply and demand defines sustainability, it proceeds by looking at challenges to supply capacity before reflecting on the challenges of meeting demand.

Food bank managers accepted that they might not always be able to meet demand, identifying a future where food banks may be forced to ration referral vouchers, with at least one food bank having already reached this position. Currently, the majority of food banks researched are using a voucher system whereby people visiting various welfare and advice agencies can receive a voucher to redeem at the food bank. For food banks using such a system, people cannot use the service without first receiving a voucher, thereby managing demand and ensuring that checks are made on people's need for food bank services. Most notably in one of the regions, a conscious decision 
had been made within food banks not to use vouchers in order to avoid denying food to anyone in need. This was far from a universal position, with some food banks feeling that this made the food banks a hostage to fortune and allowed no method of gauging genuine need. However, the food banks that did not use vouchers had made a conscious decision to not engage with conditionality, which they viewed as an increasingly prevalent element of contemporary welfare.

\section{Sustainability and challenges to supply}

Looking at current experiences of supply capacity, the food bank managers in the research identified essential supply elements, which include food donations, money, volunteers and buildings. Worryingly, over half of the managers identified at least some, if not most, of these elements as being close to capacity. Furthermore, they recognised that continued growth in demand will only be sustainably met through a growth in these supply elements. Of the elements, most managers identified volunteers as being least challenging in terms of capacity, with other elements of supply being either at or close to the point of capacity. One food bank had put a halt on volunteer while others spoke about the suitability of rooms available, and some identified cash flow as being problematic. Many managers also spoke of the types of food available, typically high-carbohydrate and low-protein food, while others identified regular shortages in areas such as toiletries, sanitary items and nappies. These findings support the point that challenges faced in sustainingVSOs go beyond income alone (Chapman, 2017).

Most of the food banks in the research benefited from collections in supermarkets as well as food donations from supermarkets and financial donations from local businesses. However, approximately a third of the food bank managers saw this as problematic as it could not always be guaranteed and some felt that their relationship with the private sector was both close to capacity and showing signs of fragility. Recognising the finite nature of supply capacity, many managers felt that supermarkets were donating less food and allowing fewer opportunities to collect.

In addition to support from private businesses, the managers identified the significant role of faith organisations in supporting capacity. The majority of food banks in the research are linked to faith organisations; mainly Christian and Muslim. However, about a half of the managers thought that this too was an area where supply was reaching capacity, for example in terms of contributions from the church/mosque as well as collections from worshippers. A further area of giving within Christian churches and many schools is Harvest Festival, where food contributions are made in September that support many food banks until the following April. But food bank managers felt that it helped during the winter but had little impact on food bank demand spikes during school holidays at Easter and in the summer.

A further area of supply linked to faith organisations was in-kind donation of offices, storage and distribution space to food banks, either free or at minimal cost. Again, this was at capacity and about a half of the food bank managers viewed this also as a fragile element of supply that could be revoked at any time if the church/ mosque needed the space for other projects. Furthermore, the food banks did not have budgets for building maintenance, which may present future challenges. A picture of food banks emerges that suggests they are increasingly close to their capacity of what they can provide. Problematically, as the next subsection examines, this is coming at a time when demand is continuing to grow. 


\section{Meeting and managing demand}

Aware of the link between supply and demand, at the same time that food banks are recognising that supply capacity is reaching its limits, stronger and more effective links with external organisations are leading to greater demand. In addition to links with private and faith sector partners, the majority of the managers identified how the food banks had developed stronger links with both local authorities and other VSOs. This included hosting advice organisations, signposting to other services and producing joint publicity materials. While the nature of this varied between food banks, it showed how food banks had become more strategic over time. This contributed to a belief among most food bank managers that food banks have become 'credible' welfare providers, addressing both the experiences and causes of hunger typified by the 'food bank plus' approach (Crisp et al, 2016).

While this has made the food banks more 'credible' organisations, a majority of food bank managers believed that it has led to increased demand through more referrals from organisations such as local authorities and advice agencies. From the interviews, it became apparent that the managers defined credibility as providing a service that was reliable, well planned and, significantly, able to fully meet demand. In other words, for the managers, being credible and sustainable meant maintaining a social purpose. However, this article questions how long food banks will be able to sustainably meet demand, especially if credibility is defined through sustainably meeting social purpose rather than solely through organisational factors. Underpinning credibility has been the development of rational managerial structures, including external engagement strategies, an element of forward planning and awareness of the needs of their clients.

As a result of more credibility and referrals, greater numbers of people are using the food banks and the food banks are increasingly aware of the breadth of people's welfare needs. As such, food banks are now distributing more than food alone; this is the case in both the Trussell Trust (Jitendra et al, 2017; Trussell Trust, 2017b) and non-Trussell Trust food banks. Food bank managers spoke of diversifying, either formally or otherwise, to offer items such as clothing, fuel vouchers, toys and cookware alongside cafés and befriending services. However, an increasingly comprehensive service coupled with stronger external links is bringing further challenges for food banks based on their increased profile and growing numbers of referrals. In effect, food banks risk being victims of their own success.

With this increased profile has also come a redefined relationship with local authorities. As a 'double-edged sword', it has seen more support from paid officers and publicity materials while also leading to increased demand. For almost all of the food banks, cuts in local authority budgets have led to increasing referrals from statutory organisations struggling to cope with their own demand. Typifying this position, one food bank manager identified how fewer housing and social workers covering larger geographical areas with fewer resources were leading to more people being referred to food banks. Reflecting a sentiment shared by many managers, one food bank manager commented that their function had changed in the eyes of these officers from emergency food aid to being a place to routinely send people whose needs they could no longer meet. Supporting this position, many of the food bank managers felt that statutory organisations now see food banks not only as credible welfare providers, but also as a convenient safety valve where people can be directed to alleviate pressures placed on statutory provision. Significantly, the food bank managers 
did not see this as being a cynical process and there was sympathy for local authority officers experiencing funding cuts, but there remained a recognition that food banks could not sustainably act as overspill agencies.

The managers interviewed saw the ability to continue to meet demand as central to credibility and sustainability. The food banks could not be seen as sustainable and successful if they operated in a way that only met a fraction of demand. But increased credibility has created a dilemma. While welcoming the wider recognition of their role of meeting people's needs in a sustainable manner and being a trusted last line of defence against hunger, there was concern that becoming indistinguishable from mainstream welfare provision could lead to a sense of entitlement from clients. This was troubling for many food bank managers who actively defined the food banks within a voluntary sector ethos of being distinct from both the market and statutory welfare.

It was against this background that food banks in two local authority areas, typifying this theme, spoke of being offered and declining service-level agreements from local authorities to provide food and support to particular numbers of people. While income from the service-level agreements would significantly boost the food banks' sustainability, there were concerns that it would damage their role asVSOs. Currently, only two food banks have been offered service-level agreements, although this is indicative of increasingly close links between larger food banks and local authorities as characterised by dedicated officer support. Returning to the initial argument, finite capacity and increasing demand are presenting challenges to food banks. Not fully meeting demand and being in a position of rationing provision might enable organisational sustainability, but it will negatively impact on the social purpose of the food banks.

\section{Discussion}

This article has, so far, reflected on how the balance between demand and supply defines sustainability. However, in the context of food banks, sustainability goes beyond organisational sustainability to also encompass food banks' ability to meet the social purpose of feeding people in need. Consequently, it is possible to reflect on the extent to which being aVSO presents both benefits and limits for sustainability as well as how food banks might change in the future. To date, food banks have been dynamic organisations that have changed significantly during the past decade. There is no reason to presume that this dynamism will come to an end.

The offer of service-level agreements touched on understandings of autonomy and a voluntary sector ethos of valuing the independence of decision making (Egdell and Dutton, 2017). While recognising that concepts of independence and distinctiveness play key roles in VSOs' identity (Macmillan, 2012), food banks currently operate what may be termed an arm's-length model of partnership working. The food bank managers in this research preferred this arm's-length model of working as they identified themselves as supporting people who have been failed by statutory welfare provision as well as the economy. In doing so, the managers recognised key failings in both systems and were not so close to risk being 'guilty by association'. For these managers, therefore, remaining distinct from businesses and government was important in defining their voluntary sector identity.

However, while this ethos was important, the managers recognised potential limitations at a time when demand is growing and supply is nearing capacity. There 
was an implicit acknowledgement that future changes may be necessary and that this may involve compromise on the issue of independence if they are to continue sustainably meeting demand.This recognises that the voluntary sector cannot operate as 'a bottomless pit' to meet increasing levels of need with little or no financial support. From the interviews, it seems likely that the future for food banks may lie in increasing partnership working, possibly with local government, although it may be that this manifests itself in different ways than service-level agreements.

While the managers saw the offer of service-level agreements as significant, it was also indicative of local authorities' need for partnerships with food banks and food banks' need for support to continue meeting demand. At the same time, for food banks, potential service limitations raise questions about the need for change within food banks and the nature of this change. Fundamentally, the choice for many food banks is a choice between either future service limitations to limit demand, or taking money, such as service-level agreements, to increase supply. This may place food bank managers in a position of choosing whether the benefits of meeting people's needs in a sustainable manner outweigh the cost of conditionality associated with an increasingly contractual relationship typified by service-level agreements.

This would represent a new role for food banks, characterised by more formal and contractual working, which might reduce their ability to make autonomous decisions. The challenge for food banks is how to retain their voluntary sector ethos while still working in a contractual manner to deliver service-level agreements. This is not without precedence - during the Labour governments of 1997-2010, significant funding was allocated toVSOs to deliver services, including service-level agreements, while retaining their independence and distinction (Ware and Todd, 2002; Roberts, 2007; Harris, 2010; Rees et al, 2012).

However, there was little evidence that food bank managers were explicitly planning for a more sustainable future despite the increasingly rational model of food bank delivery. While this position has risks when considering the demand that may lie ahead, the managers feared that an increasingly contractual relationship with local authorities would redefine the relationship between the food bank and the client, from one of voluntarism and philanthropy to one of entitlement. Furthermore, there was also a perceived risk that any move away from voluntarism could ultimately affect their supply if it led to fewer donations and less public support. However, the only way to sustainably meet increased demand will be through an expansion of the supply side of food bank provision.

Consequently, for the food banks in this research, it might be that continued growth and development comes through making changes to their voluntary sector ethos that would represent a compromise to their working practices. However, it may be that food banks have reached a point where contractual partnerships may be the only way to provide a sustainable service that can meet future challenges. For the managers, these challenges were defined in terms of external factors that prompt demand rather than internal factors such as organisational limitations. Problematically, the food banks currently have little control over these demand factors and it may be that they would have greater influence on capacity to meet demand. 


\section{Conclusions}

In conclusion, this article began by recognising the importance of sustainability within food banks; with sustainability being defined not only through organisational factors, but also through social purpose. While this is largely happening at the current time, there is a risk that demand may increase in the future, with many food bank managers feeling that supply is near to capacity. The implications for food banks are that they may face a situation of developing strategies to either increase supply or reduce the extent to which they meet demand - with the latter having implications for their social purpose. While the former may impact on the autonomy of food banks, the latter will have more egregious outcomes for the food banks' clients.

Many of the food banks now find themselves in a position where the rate of growth in food bank demand, while ongoing, has slowed sufficiently to allow space to plan for the future and reflect on their relationships with other agencies. Food banks are also now in a position to consider these links through developing partnerships based on their position as increasingly rational and credible organisations. Furthermore, food banks have a stronger relationship with their clients as they recognise the need for an increasingly comprehensive range of services and signposting.

In this context, many food banks have developed away from informal crisis intervention to provide well-organised, comprehensive and ongoing welfare for increasing numbers of people. With this being the case, sustainability is becoming more important for food banks as they provide increasingly comprehensive welfare provision. However, continuing to deliver this level of welfare remains challenging for many food banks and could become even more challenging in the future if demand grows significantly.

In this situation, food banks offer a responsive service that has little influence over the factors causing demand, such as economic and political factors or changes in local government services. However, a contractual partnership arrangement, such as service-level agreements or other funding initiatives, could enable food banks to have formalised influence over the policy process as part of taking on new responsibilities. Consequently, returning to the original question of the extent to which food banks are sustainable, responses from the food bank managers in this research identify that provision can be sustained for the time being now that the rate of increase in demand has slowed, giving food banks an opportunity to reflect on developing ways of working to effectively manage demand. However, the current position of sustainability should not be taken for granted. With further welfare reforms taking effect from April 2017, the roll-out of Universal Credit, growth in precarious working and the unknown impact of Brexit, it is not inconceivable that food banks could again see significant increases in demand and associated challenges.

Looking to the future, if food banks are to prioritise social purpose within their sustainability, they will at some point need to reflect on their current structure as they edge closer towards capacity. This research found that with fears regarding autonomy and their role asVSOs, food banks remain in a position to reject the offer of servicelevel agreements. However, as food bank demand continues to increase, future food bank growth may entail compromise as the price paid for a model of sustainability that has social purpose at its core. In terms of timing, it might be beneficial for discussions regarding future direction to take place sooner rather than later while food banks experience a period of moderate increases in demand and before a crisis point is 
reached.AsVSOs, a range of established possibilities exist. Food banks could consider developing as social enterprises to cross-subsidise food bank provision, they could develop contractual relations with local authorities that allow food banks influence over certain areas of local policy or it could be possible to consider established charity techniques of asking local people to set up monthly direct debits to support local food banks. As food banks continue to become more rational and efficient, as well as being supported by the Trussell Trust and other localised networks, it seems there is little to be gained by efficiency savings or merging to achieve economies of scale. As such, additional capacity might only be achieved by looking outside of the food banks. It can be concluded that a growing role forVSOs in the delivery of welfare, such as food aid, will ultimately necessitate comparable growth in capacity and, potentially, the ways in which that capacity is realised.

\section{Notes}

${ }^{1}$ While the job title 'manager' is used in this article, the food banks used a variety of titles, including coordinator.

${ }^{2}$ Indices of Multiple Deprivation scores are calculated by averaging super output area scores in each local authority area after they have been population-weighted. The data can also be viewed in a ranked format.

${ }^{3}$ The Black Country refers to the four local authority areas to the west of Birmingham, comprising Dudley, Sandwell, Walsall and Wolverhampton.

\section{References}

Ashton, J, Middleton, J, Lang, T, 2014, Open letter to Prime Minister David Cameron, Lancet 383, 1631, https://www.ncbi.nlm.nih.gov/pubmed/24794817

Beatty, C, Fothergill, S, 2014, The local and regional impact of the UK's welfare reforms, Cambridge Journal of Regions, Economy and Society 7, 63-79

Beatty, C, Fothergill, S, 2016, The uneven impact of welfare reform, Sheffield: Centre for Regional Economic and Social Research, Sheffield Hallam University

Black Country Food Bank Network, 2016, monitoring data, unpublished, data provided on request

Brazier, A, 2017, 'Debt strikes back' or 'the return of the regulator'? speech by Alex Brazier [online], Bank of England, 24 July, www.bankofengland.co.uk/publications/ Documents/speeches/2017/speech992.pdf

Bull, D, Harries, E, 2013, Beyond beans: Food banks in the UK, London: New Philanthropy Capital

Chapman, T, 2017, Journeys and destinations: using longitudinal analysis to explore how third sector organisational governance helps to navigate sustainable futures, Voluntary Sector Review 8, 1, 3-24

Chapman, T, Robinson, F, Brown, J, Crow, R, Bell, V, Bailey, E, 2010, What makes a third sector organisation tick? Interactions of foresight, enterprise, capability and impact, Middlesbrough:Teesside University

Cooper, N, Dumpleton, S, 2013, Walking the breadline: The scandal of food poverty in 21st century Britain, Manchester: Church Action on Poverty and Oxfam

Cooper, N, Purcell, S, Jackson, R, 2014, Below the breadline: The relentless rise of food poverty in Britain, Manchester: Church Action on Poverty and Oxfam 
Crisp, R, McCarthy, L, Parr, S, Pearson, S, 2016, Community-led approaches to reducing poverty in neighbourhoods: A review of evidence and practice, Sheffield: Centre for Regional Economic and Social Research, Sheffield Hallam University

D'Arcy, C, 2016, Midlands engine trouble: The challenges facing the West Midlands Combined Authority, London: Resolution Foundation

DCLG (Department for Communities and Local Government), 2015, English Indices of Deprivation 2015 [online], London: GOV.UK, https://www.gov.uk/government/ statistics/english-indices-of-deprivation-2015

DfE (Department for Education), 2017, NEET statistics quarterly brief: January to March 2017 [online], London: GOV.UK, https://www.gov.uk/government/statistics/ neet-statistics-quarterly-brief-january-to-march-2017

Doherty, B, Haugh, H, Lyon, F, 2014, Social enterprises as hybrid organizations: a review and research agenda, International Journal of Management Reviews 16, 4, 417-36

Dowler, E, Lambie-Mumford, H, 2014, Food aid: Living with food insecurity, Coventry: University of Warwick

Dowler, E, Lambie-Mumford, H, 2015, How can households eat in austerity? Challenges for social policy in the UK, Social Policy and Society 14, 3, 417-28

Downing, E, Kennedy, S, Fell, M, 2014, Food banks and food poverty, standard note SN06657, London: House of Commons Library

DWP (Department for Work and Pensions), 2017, Quarterly benefits summary: Data to November 2016 [online], London: GOV.UK, https://www.gov.uk/government/ uploads/system/uploads/attachment_data/file/614225/dwp-quarterly-statssummary-may-2017.pdf

Egdell,V, Dutton, M, 2017, Third sector independence: relations with the state in an age of austerity, Voluntary Sector Review 8, 1, 25-40

Ellis Paine, A, 2015, Telling tales of volunteering: Organisational insights, research findings briefing paper, Birmingham: Third Sector Research Centre, University of Birmingham

Fontaine, P, 2002, Blood, politics and social science: Richard Titmuss and the Institute of Economic Affairs, Isis 93, 3, 401-34

Forsey, A, Mason, L, 2015, A route map to ending hunger as we know it in the United Kingdom: Feeding Britain in 2015-2016, London: published by a cross-party group of Members of Parliament and peers who serve as officers on the All-Party Parliamentary Group on Hunger

Garratt, E, 2016, Food insecurity and foodbank use, CSI 28, Oxford: Centre for Social Investigation, Nuffield College, Oxford

Garthwaite, K, 2016a, Hunger pains, Bristol: Policy Press

Garthwaite, K, 2016b, Stigma, shame and 'people like us': an ethnographic study of food bank use in the UK, Journal of Poverty and Social Justice 24, 3, 277-89

Glennon, R, Hannibal, C, Meehan, J, 2017, The impact of a changing financial climate on a local UK charitable sector: voices from the front line, Public Money and Management 37, 3, 197-204

Harari, D, 2016, Regional and local economic growth statistics, briefing paper no. 05795 , London: House of Commons Library

Harari, D, 2017, Household debt: Statistics and impact on economy, briefing paper 7584, London: House of Commons Library

Harris, B, 2010, Voluntary action and the state in historical perspective, Voluntary Sector Review 1, 1, 25-40 
Harris, M, Young, P, 2010, Building bridges: the third sector responding locally to diversity, Voluntary Sector Review 1, 1, 41-58

Hood, A, Waters, T, 2017, Living standards, poverty and inequality in the UK: 2016-17 to 2021-22, London: Institute for Fiscal Studies

Iafrati, S, 2016, The sustainability of food bank provision: what happens when demand outstrips supply?, Journal of Poverty and Social Justice 24,3, 307-10

Jitendra, A, Thorogood, E, Hadfield-Spoor, M, 2017, Early warnings: Universal Credit and food banks, Salisbury: Trussell Trust

Lambie, H, 2011, The Trussell Trust foodbank network: Exploring the growth of foodbanks across the UK, Coventry: Centre for Sustainable Regeneration, Coventry University

Lambie-Mumford, H, 2013, Every town should have one: emergency food banking in the UK, Journal of Social Policy 42, 1, 73-89

Lambie-Mumford, H, 2015, Addressing food poverty in the UK: Charity, rights and welfare, paper no. 18, Sheffield: Sheffield Political Economy Research Institute, University of Sheffield

Lambie-Mumford, H, Crossley, D, Jensen, E, Verbeke, M, Dowler, E, 2014, Household food security in the UK: A review of food aid, Coventry: University of Warwick

Lindsey, I, 2008, Conceptualising sustainability in sports development, Leisure Studies 27, 3, 279-94

Loopstra, R, Fledderjohann, J, Reeves, A, Stuckler, D, 2016, The impact of benefit sanctioning on food insecurity: A dynamic cross-area study of food bank usage in the UK, Sociology Working Papers, paper no. 2016-03, Oxford: University of Oxford

Loopstra, R, Reeves, A, Taylor-Robinson, D, Barr, B, McKee, M, Stuckler, D, 2015, Austerity, sanctions, and the rise of food banks in the UK, British Medical Journal 350, www.bmj.com/content/350/bmj.h1775

Low, W, Davenport, E, 2002, NGO capacity building and sustainability in the Pacific, Asia Pacific Viewpoint 43, 3, 367-79

Macmillan, R, 2010, The third sector delivering public services: An evidence overview, working paper 20, Birmingham:Third Sector Research Centre, University of Birmingham

Macmillan, R, 2012, 'Distinction' in the third sector, Voluntary Sector Review 4, 1,39-54

Manetti, G, Toccafondi, S, 2014, Defining the content of sustainability reports in non-profit organizations: do stakeholders really matter?, Journal of Nonprofit and Public Sector Marketing 26, 35-61

Martin, G, Clift, R, Christie, I, 2016, Urban cultivation and its contributions to sustainability: nibbles of food but oodles of social capital, Sustainability 8,5 , www. mdpi.com/2071-1050/8/5/409

McCabe, A, Buckingham, H, Miller, S, with Musabyimana, M, 2016, Belief in social action: Exploring faith groups' responses to local needs, working paper 137, Birmingham: Third Sector Research Centre, University of Birmingham

Nomisweb, 2017, Local authority profiles [online], Nomisweb, https://www.nomisweb. co.uk/reports/lmp/la/contents.aspx

ONS (Office for National Statistics), 2017, People in employment on a zero-hours contract: March 2017, London: ONS

O'Toole, T, Braginskaia, E, 2016, Public faith and finance: Faith responses to the financial crisis, Bristol: Centre for the Study of Ethnicity and Citizenship, University of Bristol

Paxton, W, Pearce, N, Unwin, J, Molyneux, P, 2005, The voluntary sector delivering public services:Transfer or transformation, York: Joseph Rowntree Foundation 
Peachey, J, Smith, N, Sharma, N, 2013, Families in need of food parcels: The food poverty crisis unwrapped, Ilford: Barnardo's Strategy Unit

Pennycook, M, Cory, G,Alakeson,V,2013, A matter of time:The rise of zero hour contracts, London: Resolution Foundation

Perry, J, Williams, M, Sefton, T, Haddad, M, 2014, Emergency use only: Understanding and reducing the use of food banks in the UK, London: Oxfam

Public Health England, 2014, Children in low income families (under 16s) [online], London: Public Health England

Pyper, D, Brown, J, 2016, Zero-hour contracts, briefing paper no. 06553, London: House of Commons library

Rees, J, Mullins, D, Bovaird,T, 2012, Partnership working, research report 88, Birmingham: Third Sector Research Centre, University of Birmingham

Rees, J, Rose, N, 2015, New 'new localism' or the emperor's new clothes: diverging local social policies and state-voluntary sector relations in an era of localism, Voluntary Sector Review 6, 1, 81-91

Reisman, D, 2004, Richard Titmuss: welfare as good conduct, European Journal of Political Economy 20, 771-94

Roberts, J, 2007, Partners or instruments: can the Compact guard the independence and autonomy of voluntary organisations?, London: Centre for Civil Society, London School of Economics and Political Science

Salamon, L, Anheier, H, 1998, Social origins of civil society: explaining the nonprofit sector cross-nationally, Voluntas: International Journal of Voluntary and Nonprofit Organizations 9, 3, 213-48

Shildrick, T, MacDonald, R, Webster, C, Garthwaite, K, 2012, Poverty and insecurity: Life in low-pay, no-pay Britain, Bristol: Policy Press

Taylor, C, Donoghue, J, 2014, Towards more sustainable community organisations for older people, working paper no. 114, Oxford: Oxford Institute of Population Ageing

Tinson, A, Ayrton, C, Barker, K, Barry, T, Aldridge, H, Kenway, P, 2016, Monitoring poverty and social exclusion 2016, York: Joseph Rowntree Foundation

Trussell Trust, 2016, Food bank use remains at record high, as new data mapping tool gives fresh insight into UK hunger, press release, 15 April

Trussell Trust, 2017a, End of year stats [online], Middlesbrough:Trussell Trust, https:// www.trusselltrust.org/news-and-blog/latest-stats/end-year-stats

Trussell Trust, 2017b, More than food [online], Middlesbrough:Trussell Trust, https:// www.trusselltrust.org/what-we-do/\%20more-than-food

Tsilimpounidi, M, Sampson, A, Voela, A, 2014, Food banks in East London: Growth by stealth and marginalisation by the state, London: Centre for Social Justice and Change, University of East London

Wales, T, 2013, Organizational sustainability: what is it and why does it matter?, Review of Enterprise and Management Studies 1, 1, 38-49

Ware, P,Todd, M, 2002, British statutory sector partnerships with the voluntary sector: exploring rhetoric and reality, Social Policy Journal 1, 3, 5-16 